\title{
Early Warning and Early Response: The Link between Information and Action
}

\author{
Kathryn Whidden
}

\begin{abstract}
While there are many agencies and states which actively monitor early warning information, few have the added challenge of linking their analysis of the information with their actions in the field. This article explores the operational reality of the International Red Cross and Red Crescent Movement, arguing that there is not a monolithic early warning system which will meet the needs of all players.

\section{Précis}

Alors qu'un grand nombre d'agences et d'états suivent de très près la circulation des informations concernant l'alerte préventive, très peu font face au défi supplémentaire consistant à établir le lien entre les informations dont ils disposent et leur action sur le terrain. Cet article explore la réalité opérationnelle de la Croix Rouge Internationale et du Mouvement Croissant Rouge, en développant une argumentation selon laquelle il n'existe pas un système monolithique d'alerte préventive qui rencontrerait les besoins de la totalité des intervenants.
\end{abstract}

For international organizations providing emergency relief, an effective early warning system functions much like a living strategic plan. Information from the early warning system is analyzed and operational decisions are taken based on this analysis. The link between analysis and action is often

Kathryn Whidden has worked as an International Seroices Officer at The Canadian Red Cross Society in Ottawa since 1993. She is currently responsible for operations in Central and Easterm Europe, having done monitoring and evaluation missions in Bosnia, Russia and other regions of the world.

The views expressed here are the personal views of the author and do not necessarily reflect the oiews of the Red Cross. made within a very short time. Other times, there is opportunity for prolonged reflection and in these circumstances one has to be vigilant in monitoring, careful not to miss a fluctuation in the indicators.

For Red Cross, the main issue at stake with regard to "synergy in early warning" is how best to serve the interests of the victims, or potential victims, in an effective and coherent way. Priority attention is also paid to increasing the strength of local coping mechanisms. Much of the early warning information comes from this level of the system and, in addition, any response which may be planned must be carried out in conjunction with structures and capacities which are already present.

\section{Early Warning: the Red Cross Context}

In the International Red Cross and Red Crescent Movement, players come from one of three components: the National Societies, the Federation and the International Committee of the Red Cross (ICRC). A brief explanation of the organization of the Red Cross system at this point allows for a more detailed contextual analysis of our operations later on in the paper.

To begin, there exist 171 National Red Cross or Red Crescent Societies around the world. Considering the additional "National Societies in formation," there is virtually a Red Cross or Red Crescent presence in almost every country in the world, forming a truly international network of assistance. The Societies must fulfil stringent conditions to become recognized and to gain membership in the Movement. They must carry on humanitarian work throughout the territory of their country. They must respect the seven Fundamental Principles ${ }^{1}$ of the Red Cross and Red Crescent Movement and be recognized by their governments as voluntary aid societies which act as auxiliaries to the public authorities. Additionally, special status under International Humanitarian Law (IHL) gives National Societies and the ICRC a privileged role and responsibility in relation to victims of armed conflicts. National Societies provide a range of services, including emergency relief, health services and social assistance, to those individuals considered most vulnerable and most in need. They are responsible for disseminating information on IHL. In wartime, National Societies may act as auxiliaries to the army medical services, aid prisoners and refugees and provide a tracing service to help put people in touch with missing relatives.

The International Federation of Red Cross and Red Crescent Societies (the Federation), founded in 1919, is the permanent liaison body of the $\mathrm{Na}$ tional Societies. The Federation is the element of the Red Cross which organizes and coordinates international response to natural disasters and to the population movements (namely refugees) which result from conflict. The Federation further assists all National Societies in developing their capacity to effectively manage staff, volunteer and governance structures, as well as programs.

The ICRC was created in 1863 and is the founding body of the Movement. A Swiss-governed institution, the ICRC acts to protect and assist victims of international and internal civil conflicts, and has official responsibilities set out in the four Geneva Conventions and the two Additional Protocols. Associated tasks include the unique mandate of monitoring the treatment of prisoners of war, and a right of humanitarian initiative recognized by the international community. The ICRC is a

Refuge, Vol. 16, No. 1 (May 1997) 
neutral, impartial and independent humanitarian institution.

Both the Federation and the ICRC maintain a decentralized network of regional delegations spread out across the world, as well as a host of active country delegations. The country delegations manage the territory-specific operations; often this includes management of a relief operation. The regional delegations assist the cluster of country delegations in their jurisdictions, while also bringing a wider geographic perspective to the operations.

This combination of National Societies, country delegations, regional delegations and Geneva headquarters adds up to a Movement which, with staff and volunteers, directly includes over $250,000,000$ individuals. The decentralized grassroots structureallows Red Cross to be there- on the spotresponding to crises effectively and rapidly.

\section{Early Warning Information is ... What? For Whom? Starting When?}

Organizations seek early warning information for different reasons, depending on their own unique mandate.

There does not exist a monolithic, all-encompassing Red Cross early warning system. As with most organizations, the various offices of the Red Cross seek information from many sources, depending on its unique needs. In fact the early warning terminology would, in our case, be better expressed as "trend" or "horizon scanning." It means accessing the type of information required to do our job-to assist beneficiaries.

To assist us and similar organizations, there are already many related early warning systems and tools. What they provide is raw material-information which can be subject to a variety of interpretations. As an example, the inflation rate in an economically troubled country is a piece of raw data. Having analyzed this rate, a social services organization may then call for a fight against the associated rise in child poverty. A government agency may use the statistic as a rationale for budget cuts. A bank may see a necessity to raise the interest rates. A group representing elders may use such a statistic to lobby for the need for an increase in pensions.

Within the context of a complex conflict, the nuances of meaning surrounding one statistic or one bit of information are subject to the same variations of perception. Added to the variances can be a political or ethnic fervour which, in and of itself, further skews the interpretation.

While some data, such as inflation rates or information about political prisoners, may be released on a regular schedule, there are other bits of early monitoring. One seeks to analyze from a national or regional perspective, while the other functions at a local or community level.

The macro-triggers provide data which monitors the humanitarian situation from a national or international perspective. This includes the trends in national/regional politics (such as the monitoring of political forces, military presence, ethnic factors, demographic trends); trends in the geopolitical context; in international health (i.e., the rate and transmissibility of disease); in national/regional security issues; in satellite climatological/agronomical data, and the presence and operations of interna-

If the roots of a situation, such as that of Hutus and Tutsis in
Rwanda, goes back over generations-when does a warning no
longer merit being called "early"? Given the ethnic composition and
historical troubles in many regions of the world, there are already
well-defined parameters for potential conflict. There would thus be
little reason to call a warning "early," but rather "perpetual."

warning information which are more creeping in nature. It is difficult, for example, to quantify the extent of racism or ethnic hatred in a region. For information of this nature, it is the choice of the individual analyst as to how far back one needs to go in time to track a situation. If the roots of a situation, such as that of Hutus and Tutsis in Rwanda, goes back over generations-when does a warning no longer merit being called "early"? Given the ethnic composition and historical troubles in many regions of the world, there are already well-defined parameters for potential conflict. There would thus be little reason to call a warning "early," butrather "perpetual."

For this reason, it is not realistic to speak of a monolithic "early warning system." There is a semblance of a system which exists, yet it exists only to aggregate information.

\section{Early Warning: Big Picture and Small Picture}

There are essentially two intertwined early warning systems which require tional actors (diplomatic, humanitarian, religious).

There is an international system for monitoring these macro-triggers, yet each player seeks information related to their specialized mandate. These players include, yet are not limited to: the United Nations system, the Organization for Security and Cooperation in Europe (OSCE), the media, all individual states and their embassies, international organizations, NGO's and universities.

Functioning at a lower level, the micro-triggers provide data which monitors the humanitarian situation from a local or community perspective. Some of that which is monitored has previously been mentioned, yet the narrower perspective influences what one may see in the data, thus the interpretation may not be the same. Micro-triggers include, but are not limited to, the following:

- the political situation;

- climatic conditions and food security/availability/access; 
- market prices/market background information;

- the activities of international organizations and NGO's;

- security situation;

- public health situation, including the state of health facilities;

- population movements;

- "at risk" populations;

- agriculture, including land preparation trends, rainfall and germination, crops, yield estimates;

- detainees situation; and

- human rights situation.

A final micro-trigger looks at the use of a population's coping mechanisms or "insurance" policies. This could take many forms and includes the following:

- changes in cropping and planting practices;

- dispersed grazing;

- migration in search of employment;

- increased petty commodity production;

- collection of wild foods;

- use of inter-household transfers and loans;

- use of credit from merchants and moneylenders;

- rationing of current food consumption or slimming;

- consumption of relief food;

- sale of productive assets; and

- break-up of household and distress migration.

There are many different organizations which monitor the micro-triggers and, in various ways, provide the associated information. These includelocal governments, religious and cultural groups, community and neighbourhood associations, local public health authorities, Red Cross or Red Crescent Societies and many other players.

It is important for those larger agencies which focus on the macro-perspective to compare their national or international conclusions with that of the local perspective. Often the macroindicators may paint a different picture than that which is viewed at the local perspective. While there may be legitimate reasons for this, that level of comparative analysis is important to undertake in order to develop a comprehensive view of a situation.

\section{How Do We Gather and Analyze Information?}

The information yielded through the systems mentioned above is raw data. It does not form a single mechanism for early warning which can be assessed by all interested players. Thus, the data requires analysis and interpretation to become meaningful and this is a task undertaken by all individual players, using their own specialized mandate as a filter.

Using terminology of a paper presented by William DeMars (1997), ${ }^{2}$ who assessed the utility of data gathered by NGOs for early warning purposes, one pragmatic response is that the variety of NGO eyes and ears are attached to differentheads. Where that head is, and what it looks like, will influence how it gathers and interprets data. Is it black? White? Male? Female? Religious? Independent or organizationally-based? Canadian? African? These factors can influence what the eyes see, and what the ears hear. Likewise, what an early warning indicator is and how or if you should react, depends enormously on who you ask.

Having accessed raw data, there are a number of steps to take in assessing it. For the purpose of assessing what could be early warning information, relief organizations need to constantly test the validity of information gathered. To do so, they first ensure that those doing the data gathering are well-trained. Preferably there are multidisciplinary teams working together. In addition, organizations must analyze the data gathering system/trends to ensure that respondents are not seeking to manipulate a possible response.

Within the Red Cross and Red Crescent Movement, the National Societies engage the local population in training, in networking and risk analysis. In this way, there are local people monitoring early warning indicators which they themselves find to be meaningful. Ideally, this is part of a disaster preparedness and prevention (DPP) program, linking the capture of information to the need for action, given certain defined scenarios.

Another element of early warning data analysis is that of determining the cause for changes to raw data. If trends change, how can this be explained? What are the repercussions or consequences of this change? In this way, the analyst attempts to stay a step or two (or three) ahead of an unfolding scenario. In the case of Red Cross, this often brings about the pre-positioning of food or medical stocks. In situations when troops are called to action, it can also bring about renewed ICRC efforts to train armed forces in international humanitarian law, ensuring that soldiers understand the rules of war.

\section{The Importance and Difficulty of \\ Having a Neutral Approach in the Gathering of Information}

Yet the context of an increasing proportion of operations today is often having little to do with organized armed forces. New armed actors of violence often do not represent nations, but rather economic, ethnic, religious interests or even organized crime. This growth of criminal behaviour and banditry imposes a new approach the context of unstructured conflicts where basic rules are not respected. It necessitates a new horizon-scanning approach for relief agencies, one which includes players not normally recognized as valid interlocutors.

Other trends which affect security of Red Cross/Red Crescent operations include the fact that humanitarian action is becoming increasingly attached to Western values and as such, are perceived to represent enemies by some parties to a conflict. Further, humanitarian action is in contradiction with the very aims of what are known as conflicts of identity or conflicts of a genocidal nature.

Despite the vast expanse of data which can be gathered from the plethora of information sources today, it can become more and more difficult to have a clear picture of the humanitarian community owing to 
interagency competition, overlapping mandates, militarization and politicization. This situation is exacerbated by rampant mediatization which results in a blurred conception of each agency's mandate and may cast doubt on an operation's independence and neutrality.

The media, through its field presence and pursuit of news in time for deadlines and often for commercial purposes, comes to play a role which extends far beyond that of mere observer. This has a ripple effect for agencies which compete for media attention, as profiling of organizational logos in the international media comes to be equated with success for the entire operation. Additionally, the media pursues and distributes information from many of the same sources used by relief agencies. In being quoted as a media sourse, an agency may have jeopardized the extent to which it can subsequently collect information. This forces a degree of accountability from agency representatives and a sharp understanding of information, as well as the role of disinformation.

The data-gathering job is thus often not one which is, in itself, neutral. Particularly in the context of today's unstructured conflicts, there are many interlocutors who must be included in an agency's horizon-scanning. Each has their own agenda and seeks to provide information which furthers this platform. Agencies must be diligent in their own collection of information, ensuring that all parties and subgroups are consulted-aware that each has its own bias.

\section{The Link Between Information and Action}

As relief organizations must tie their analysis to their subsequent actions, attention is always paid to the local individual and group coping mechanisms. When are they being used? When are they being challenged? When are they being overwhelmed? This brings an organization to the point of then deciding when is an appropriate and necessary time to respond.
The option of response is always analyzed against the strength of local coping mechanisms. Much like a disaster, an international response may challenge and/or overwhelm the local capacities. Possible interventions are assessed for the degree to which they would be likely to make the transition to longer-term development projects, as well as the degree to which it may impact the local, national or international political scene.

Ideally, a response initiative is preventive in nature, seeking to avoid early warning system, not all organizations are expert in monitoring an early warning system-nor should they be. A traditional development project must certainly understand the context in which it is operating yet, if it is a project focused on childhood immunization, let us not expect it to likewise provide an analysis of national political trends.

The limitations of an organization's mandate will govern the degree to which it is involved in an assessment of early warning information, likewise

\section{It would be unwise to believe that every organization which has a hand in feeding an early warning system will likewise be a part of a response which is eventually staged. While it is believed that early warning information should be tied to early action, it is often not appropriate for a multiplicity of agencies to be involved in this action.}

human suffering. While the prescriptive actions associated with avoiding a natural disaster are relatively straightforward, those associated with avoiding conflict are more complex.

It would be unwise to believe that every organization which has a hand in feeding an early warning system will likewise be a part of a response which is eventually staged. While it is believed that early warning information should be tied to early action, it is often not appropriate for a multiplicity of agencies to be involved in this action. This is particularly true in the case of a complex disaster.

Within the Red Cross and Red Crescent Movement, it is the National Society which is the "first responder." Through the prepositioning of volunteers trained in first aid and disaster preparedness and prevention, they are in a position to be informed about pending disasters and to be at the scene as it unfolds. Following from this, it is clear that each element of the Red Cross and Red Crescent Movement plays its own special role in disaster prevention, response or mitigation.

Likewise, each organization involved in early warning and response plays its own role. While all may formally or informally feed each others it will govern the degree to which the organization is involved in a response initiative.

\section{What Next?}

Ultimately, an effective early warning system is but one step. Receiving appropriate and accurate raw data is important, as is the data analysis. Yet even if the coordination and collaboration among the various agencies were improved, the world may not emerge a safer place.

1) Response agencies need to continually assess and validate their data. The "early" warning is timeless in that it represents a constant, cyclical approach to monitoring, assessing, analyzing and comparing.

2) The root causes of conflicts and disasters need to be addressed. Early warning, followed by early humanitarian response, often does little more than provide victims a temporary respite. There are no technical solutions to political problems and the humanitarian agencies are not, by virtue of their own mandates, able to provide the political solutions.

3) The impact of international assistance needs to be measured against the possibility of finding a more 